\title{
O papel da Fisioterapia nas escolas e na sala de atendimento educacional especializado (AEE): uma revisão não sistemática
}

\author{
The role of physiotherapy in schools and in the specialized \\ educational care (ESA) room: a non-systematic review
}

\author{
Martha de Oliveira Pinheiro' \\ Tainá Ribas Mélo²
}

\section{RESUMO}

Por muito tempo os deficientes físicos foram mantidos excluídos da sociedade, porém nos últimos anos esta situação vem se modificando e se discutindo a inclusão dessas crianças e adolescentes na comunidade. Esse estudo buscou discutir a atuação do profissional fisioterapeuta no ambiente escolar e na sala de atendimento educacional especializado (AEE), verificando na literatura os meios de atuação do profissional fisioterapeuta. Essa pesquisa trata-se de uma revisão não sistemática de bases de dados indexadas e google acadêmico. As maiorias dos estudos selecionados relacionavam a atuação do fisioterapeuta em relação a aspectos de mobiliário / adaptação ambiente físico, minimização de barreiras arquitetônicas. Alguns relatam a ação do fisioterapeuta na escola com relação à identificação do Desenvolvimento Neuropsicomotor (DNPM), assim como no esclarecimento de dúvidas pertinentes a esse DNPM e outros abordam sobre a importância da troca de experiências entre o fisioterapeuta e os professores, a cerca de educação em saúde, sobre como agir com os alunos. Por meio deste estudo evidencia-se a importância do profissional fisioterapeuta atuando interdisciplinarmente com outros profissionais, no ambiente educacional, como também na atenção primária, o qual se preconiza a prevenção.

\section{PALAVRAS-CHAVE}

Atendimento Educacional Especializado, Fisioterapia, Inclusão.

\footnotetext{
'Fisioterapeuta (UFPR), Acadêmica do Curso de Sociologia (UNOPAR), da Pós-graduação em Neurologia com ênfase em Neuropediatria da Faculdade de Tecnologia IBRATE e da pós-graduação em educação especial a distância pela Bagozzi. ${ }^{2}$ Fisioterapeuta, Doutoranda em Atividade Física e Saúde (UFPR), Docente da Uniandrade e do Curso de Pós-graduação em Neurologia com ênfase em Neuropediatria da Faculdade de Tecnologia IBRATE.
} 


\section{ABSTRACT}

For a long time the disabled people were kept excluded from society, but in recent years this situation has been changing and discussing the inclusion of children and adolescents in the community. This study aimed to discuss the role of the physiotherapist in the school environment and in specialized education room (ESA), checking the literature the means of physical therapist practice. This research it is a non-systematic review of indexed databases and academic google. The majority of the selected studies related the role of the physiotherapist in relation to aspects of furniture / adapted physical environment, minimizing architectural barriers. Some report the physiotherapist action in school regarding identification neuropsychomotor Development (DNPM), as well as to clarify pertinent questions to this DNPM and other address on the importance of exchanging experiences between the therapist and teachers, about education in health, on how to act with the students. Through this study highlights the importance of professional physiotherapist working interdisciplinary with other professionals in the educational environment, but also in primary care, which is called for prevention.

\section{KEYWORDS:}

Educational Service, Physical Therapy, Inclusion 


\section{INTRODUÇÃO}

Por muito tempo os deficientes físicos foram mantidos excluídos da sociedade, porém nos últimos anos esta situação vem se modificando e se discutindo a inclusão dessas crianças e adolescentes na comunidade, sendo vistos como sujeitos de direito, assim como todos os indivíduos, independente de sua condição, tendo o direito a cultura, lazer, transporte, serviços sociais e de saúde, oportunidades de trabalho e educação (NIEHUES; NIEHUES, 2014).

A escola inclusiva tem como princípio fundamental que todas as crianças possam aprender juntas, independente de suas dificuldades ou diferenças. As escolas inclusivas devem reconhecer e responder às diversas necessidades dos alunos, assegurando uma educação de qualidade, por meio de currículo apropriado, modificações organizacionais, estratégias de ensino, uso de recursos e parcerias com a comunidade. Devem também, oferecer as crianças com necessidades especiais qualquer apoio extra de que possam precisar, para lhes assegurar uma educação efetiva (FERRAZ et al., 2010).

No Brasil, o Atendimento Educacional Especializado (AEE) é uma proposta para o apoio à inclusão escolar de alunos do público alvo da Educação Especial, no turno inverso à escolarização. $O$ professor atuante neste ambiente deve organizar as atividades e recursos pedagógicos e de acessibilidade, a fim de facilitar o processo de aprendizagem dos alunos da Educação Especial. Entende-se que as atividades propostas do AEE não é um reforço escolar e sim, um apoio ou suplementação. É importante que haja uma organização escolar para que a equipe da escola consiga discutir, entender e promover transformações na sua organização e funcionamento para atender os diversos tipos de necessidades (SILVA et al., 2014). Kassar e Rabelo (2011) definem o atendimento educacional especializado, como sendo um meio pelo qual o aluno com deficiência possa atingir o pleno desenvolvimento das suas potencialidades e assim seja integrado. Ou seja, esse atendimento é necessário para que se atinjam os objetivos propostos e sua ausência impossibilitaria alcançá-los, reconhecendo-se, portanto, que os alunos considerados deficientes devam receber um atendimento educacional que seja diferenciado.
Para Bridi (2009) a Educação Especial, no contexto da Política Nacional de Educação Especial na perspectiva da Educação Inclusiva, é definida como uma modalidade de ensino que perpassa todos os níveis, etapas e modalidades de educação. $\mathrm{O}$ atendimento educacional especializado identifica, elabora e organiza recursos pedagógicos e de acessibilidade que eliminem as barreiras para a plena participação dos alunos considerando suas necessidades específicas. As atividades desenvolvidas no atendimento educacional especializado diferenciam-se daquelas realizadas na sala de aula comum, não sendo substitutivas à escolarização. Esse atendimento complementa e/ ou suplementa a formação dos alunos com vistas à autonomia e independência na escola e fora dela.(...) Ao longo de todo o processo de escolarização, esse atendimento deve estar articulado com a proposta pedagógica do ensino comum sendo muitas vezes necessário apoio multiprofissional para que sejam atendidas a maioria das demandas dessas crianças (BRASIL, 2008).

Para Lima \& Silva e Mazzotta (2009) os fisioterapeutas estão a cada dia mais envolvidos na inclusão escolar e na participação das crianças em situações escolares, pelo fato de o objeto de estudo do fisioterapeuta ser o movimento humano e as alterações do mesmo, torna-se preparado para facilitar a inclusão escolar de crianças com deficiência física e/ou múltipla e torná-la mais capaz e inserida na sociedade. Além disso podem ser aliados no processo de inclusão e capacitação dos profissionais das escolas e de orientação aos pais/familiares. Com relação aos profissionais da escola, esses muitas vezes relatam despreparo, ou apresentam resistência para aceitar a inclusão dos alunos devido às suas dificuldades. Com relação aos pais é comum que sejam descrentes das potencialidades dos filhos com deficiência. Apesar da possibilidade de atuação do fisioterapeuta na escla e na sala de AEE e da mesma já ser uma prática, são escassos os estudos sobre essa temática (SANTOS et al., 2014).

Com base nesses pressupostos teóricos até aqui apresentados, objetivou-se realizar uma revisão não sistemática referente à atuação do profissional fisioterapeuta na sala de atendimento educacional especializado (AEE). 


\section{MÉTODOS}

Essa pesquisa trata-se de uma revisão não sistemática (ROTHER, 2007) devido à impossibilidade de ser finalizada uma revisão sistemática (SAMPAIO; MANCINI, 2007; DE-LA-TORRE-UGARTE et al., 2011) seguindo todas as recomendações necessárias, mas havendo a necessidade de se revisar as evidências existentes (COSTA et al., 2011) até o momento das possibilidades de atuação do fisioterapeuta na escola e no AEE. Primeiramente buscou-se por artigos em bases de dados indexadas (Scielo, LILACS, MEDLINE) por meio das palavras-chave (Atendimento Educacional Especializado e fisioterapia, inclusão e fisioterapia), porém, apareceu zero resultado, o que leva à tona, a necessidade de mais estudos sobre a temática.

Optou-se então, pela busca no google acadêmi$\mathrm{co}$, de artigos que se relacionassem com o tema proposto desse estudo, porém, com esses mesmos descritores também foram encontrados zero resultado. Portanto, buscou-se por artigos de maior relevância (bases indexadas, dissertações, teses) que se relacionassem com o tema proposto, sendo as palavras cha- fisioterapeuta no ambiente escolar corroborando com Santos, Lara e Folmer (2014) e também, na sala de atendimento especializado (AEE), este fato, pode ser devido à profissão culturalmente ser conhecida mais com foco curativo/reabilitador , sendo necessária uma mudança de paradigmas.

Portanto, pela carência de material teórico relacionado com a temática proposta inicialmente, se obteve certa dificuldade na elaboração desse estudo. A tabela 1 apresenta os principais estudos selecionados e considerados mais relevantes com o tema proposto e os seus principais resultados, apontando a atuação do fisioterapeuta no ambiente educacional, mais precisamente, no atendimento educacional especializado.

De maneira geral observa-se que dos 12 estudos incluídos nessa revisão, a maioria dos estudos selecionados que relacionam a atuação do fisioterapeuta no $\mathrm{AEE}$, aborda a fisioterapia em relação a aspectos de mobiliário / adaptação ambiente físico, minimização de barreiras arquitetônicas (DURCE et al., 2006; ALPINO, 2010; GALLO et al., 2011; SARAIVA; MELO, 2011). Alguns relatam a ação do fisioterapeuta na escola com relação à identificação do Desenvolvimento Neuropsicomotor - DNPM, assim como no esclarecimento de dúvidas pertinentes a esse DNPM (DURCE et al., 2006; TAGLIARI et al., 2006; JORQUEIRA NETO; BLASCOVI-ASSIS, 2009; ALPINO, 2010) e outros abordam sobre a importância da troca de experiências entre o fisioterapeuta e os professores, a cerca de educação em saúde, sobre como agir com os alunos (TAGLIARI et al., 2006; JORQUEIRA NETO; BLASCOVI-ASSIS, 2009; MELO; FERREIRA, 2009; NIEHUES; NIEHUES, 2014; SANTOS et al., 2014; SILVA et al., 2014; CHESANI et al., 2015). Além desses artigos selecionados, foram também usados outros estudos que citavam sobre a importância do fisioterapeuta no ambiente educacional, como forma de complementação.

Com base nos artigos selecionados, ratificase a relevância do profissional fisioterapeuta também no ambiente escolar, com papel de promoção e prevenção de saúde, ao considerar que o exercício da fisioterapia nas instituições de ensino é assegurado pelo código de ética profissional,: "É atividade privativa do fisioterapeuta executar métodos e téc- 


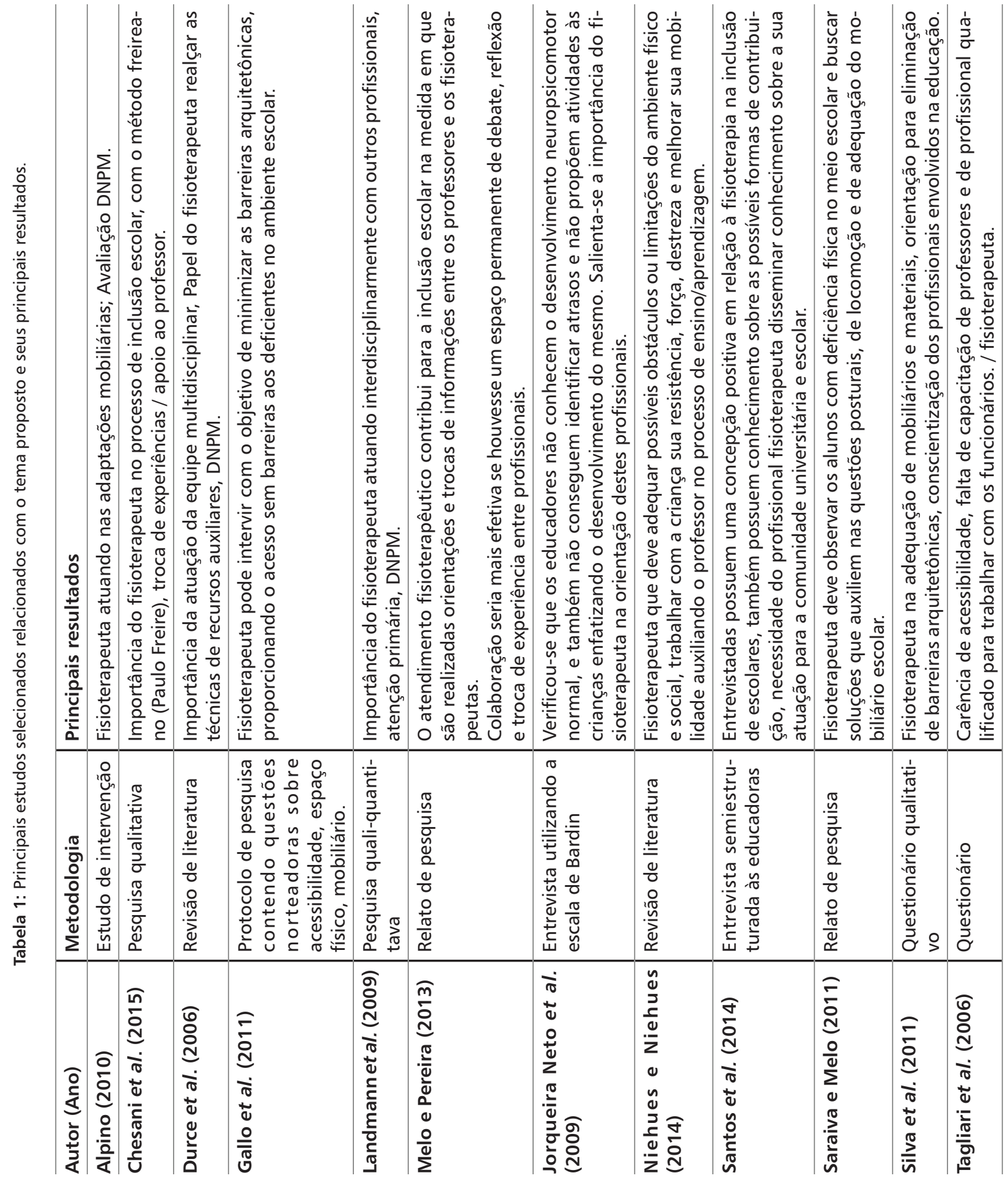


nicas fisioterapêuticas com finalidade de restaurar, desenvolver e conservar a capacidade física do paciente (COFFITO)". Assim a atenção fisioterapêutica propicia o desenvolvimento de ações preventivas primárias, secundárias e terciárias (LANDMANN et al., 2009) com crianças típicas em desenvolvimento, assim como com orientação da equipe escolar.

O Fisioterapeuta tem papel preponderante no ambiente escolar uma vez que poderá por meio de suas atribuições e conhecimento específicos, propor mudanças e inovações não somente externa como internamente, possibilitando melhores condições de acesso e permanência do portador de deficiência física proporcionando sua inclusão no ambiente escolar e assim melhorando a sua qualidade de vida (TAGLIARI et al. , 2006).

Em ambiente de creches predominantemente há um foco sobre a investigação psicomotora (BRAGA et al., 2011) sendo que muitas vezes não há uma proximidade do fisioterapeuta na organização das ações da escola, mas sim com participação pontual em avaliações de crianças, orientações a pais e professoras (GUIMARÃES et al., 2015).

Em relação aos recursos humanos Saraiva e Melo (2011), consideram que além do professor, é necessária uma equipe bem integrada que inclua profissionais de outras áreas. Entre estes, os da área da saúde como o fisioterapeuta e o terapeuta ocupacional assumem importante papel no trabalho conjunto à equipe da escola, observar os alunos com deficiência física no meio escolar e buscar soluções que auxiliem essas pessoas no que se referem, entre outros aspectos, às questões posturais, de locomoção e de adequação do mobiliário escolar. O fisioterapeuta em conjunto aos docentes da escola pode por meio de brincadeiras adaptadas, como gincanas, mímica, boliche, arremesso na cesta de basquete, jogos com bola, xadrez, jogos de quebra-cabeça, jogos de peças e de memória, alongamentos, relaxamentos, entre outras, podem estimular o desenvolvimento da criança deficiente física. Pois através destas, estimula-se na criança a sensibilidade epicrítica e tátil (discriminar textura, peso, tamanho), desenvolve-se habilidades motora (agarrar, manusear, jogar), ou seja, trabalha-se tanto motricidade fina quanto a ampla com esses alunos (NIEHUES; NIEHUES, 2014).
No que diz respeito à atuação na sala de atendimento especializado, Moraes (2004) considera que cabe ao fisioterapeuta instruir o professor sobre o posicionamento e manuseio para a criança portadora de deficiência física, por exemplo, bem como orientá-lo na seleção e uso de equipamentos, mobiliários, dispositivos de suporte, adaptação e facilitação dos padrões posturais, tanto no ambiente da sala de aula como em atividades extra-classe. Lorenzini citado por Melo e Ferreira (2009) menciona que cabe ao fisioterapeuta instruir o professor sobre o posicionamento adequado para determinada deficiência física; assim como orientá-lo na seleção e uso de equipamentos, mobiliários, dispositivos de suporte, adaptações e facilitação dos padrões posturais, bem como condições de funcionalidade do aluno, tanto no ambiente em sala de aula como em atividades extra-classe, como passeios, jogos recreacionais, enfim, em qualquer atividade.

Para Lima \& Silva e Mazzotta (2009) os fisioterapeutas estão a cada dia mais envolvidos na inclusão escolar e na participação das crianças em situações escolares, pelo fato de o objeto de estudo do fisioterapeuta ser o movimento humano e as alterações do mesmo, torna-se preparado para facilitar a inclusão escolar de crianças com deficiência física e torná-la mais capaz e inserida na sociedade. Evidencia-se também o despreparo dos professores, a resistência das escolas para aceitar a inclusão dos alunos e pais descrentes das potencialidades dos filhos com deficiência. Durce (2006) considera que o papel do fisioterapeuta, no que se refere ao trabalho com crianças portadoras de deficiência física em escolas regulares, visa transmitir habilidades fundamentais para contribuir com o professor e outros profissionais, tentando minimizar as dificuldades dessas crianças objetivando um desenvolvimento máximo de suas potencialidades. Machado (1999) afirma que o fisioterapeuta pode atuar orientando sobre as condições motoras do indivíduo ao educador físico e demais professores para que situações como essas deixem de ocorrer, efetivando o trabalho de inclusão do aluno portador de deficiência física em todas as atividades realizadas na escola e, assim, torná-lo mais participativo no grupo de colegas. Vitta et al. (2000) considera que o fisioterapeuta, ao trabalhar preventivamente junto 
às condições de saúde, poderá fornecer um repertório de conhecimentos sobre o desenvolvimento motor infantil aos profissionais da educação.

O fisioterapeuta deve ser observativo e tentar aprender quais as esperanças e expectativas da criança e de seus pais, isso facilita o desenvolvimento de um programa mais relevante, estimulando o movimento na sala de aula, ou externamente, no ambiente educacional. Esse programa pode ser meIhor elaborado junto as ideias dos professores. Deve ser mantido um contato agradável entre os pais da criança, fisioterapeuta e professores, para se obter uma melhor resposta ao trabalho (KAVALCO, 2003).

$\mathrm{O}$ fisioterapeuta juntamente com uma equipe formada por diferentes profissionais da saúde pode participar de orientações escolares, identificando as barreiras que a criança vai enfrentar no ambiente escolar, bem como as expectativas e as exigências para ela poder funcionar nesse ambiente (LANDMANN et al., 2009). Melo e Ferreira (2009) mencionam que cabe ao fisioterapeuta instruir o professor sobre o posicionamento adequado para determinada deficiência física; assim como orientá-lo na seleção e uso de equipamentos, mobiliários, dispositivos de suporte, adaptações e facilitação dos padrões posturais, bem como condições de funcionalidade do aluno em qualquer atividade no ambiente escolar.

Autores (CHESANI et al., 2015) consideram que o fisioterapeuta deve intervir e auxiliar no processo de inclusão escolar dentro da equipe por meio de ações como: orientação sobre a condição da deficiência física; quanto ao posicionamento e postura adequados; prevenção de complicações decorrentes da deficiência física; eliminação de barreiras arquitetônicas e a importância do espaço acessível; adaptações de materiais e mobiliário escolar; auxílio às famílias para encontrarem recursos comunitários apropriados; colaboração junto às instituições no sentido de integrar o aluno à comunidade; habilitar o aluno com deficiência física com movimentos e posturas favoráveis à realização das tarefas escolares, entre outros aspectos.

Sobre a perspectiva da inclusão escolar, Alpino (2010) considera que a atuação do fisioterapeuta não é e não deve ser terapêutica, mas coadjuvante, no sentido de buscar as adaptações necessárias para favorecer uma maior independência e autonomia do aluno com deficiência física, visando oportunizar um melhor aprendizado e uma melhor socialização no contexto escolar. O fisioterapeuta busca, então, através de sua visão global e de seus conhecimentos a respeito do desenvolvimento neuropsicomotor normal, facilitar a aquisição / aprimoramento de certas habilidades e conceitos necessários, prévios ao processo de alfabetização, através de palestras, orientações e troca de experiências com os educadores (LANDMANN et al., 2009). A atuação do fisioterapeuta na escola se faz principalmente sob a ótica da restrição de participação, na tentativa de adequar o ambiente de acordo com a capacidade do aluno e, também, intervir no campo social, modificando, de certa forma, atitudes e posicionamentos da comunidade escolar (MELO; PEREIRA, 2013).

Ou seja, o fisioterapeuta poderia intervir no ambiente escolar, mais precisamente na sala de $A E E$, fazendo parte de uma equipe multidisciplinar em que possa haver a troca de experiências com os demais profissionais. Atuando também, nas adaptações mobiliárias, psicomotricidade através de realizações de atividades lúdicas, orientações aos professores em relação aos manuseios e posturas adequadas e também a cerca de desenvolvimento neuropsicomotor, como aponta a figura 1 (na página seguinte).

A proposta da inclusão escolar ao aluno com deficiência como parte integrante do trabalho do fisioterapeuta desponta para mais um desafio (DURCE et al., 2006). A questão não tem uma assertiva, mas sim uma proposta de exploração para um campo de atividade de um profissional que lida diretamente com as famílias e quer ampliar o horizonte de conhecimentos sobre o segmento da sociedade que tem sido descriminada na escola. Ou seja, é necessário que haja um processo de capacitação do profissional da educação para lidar com esse público e também, uma conscientização acerca de que o profissional fisioterapeuta pode trabalhar em conjunto. 
Figura 1: Atribuições do fisioterapeuta na sala de AEE

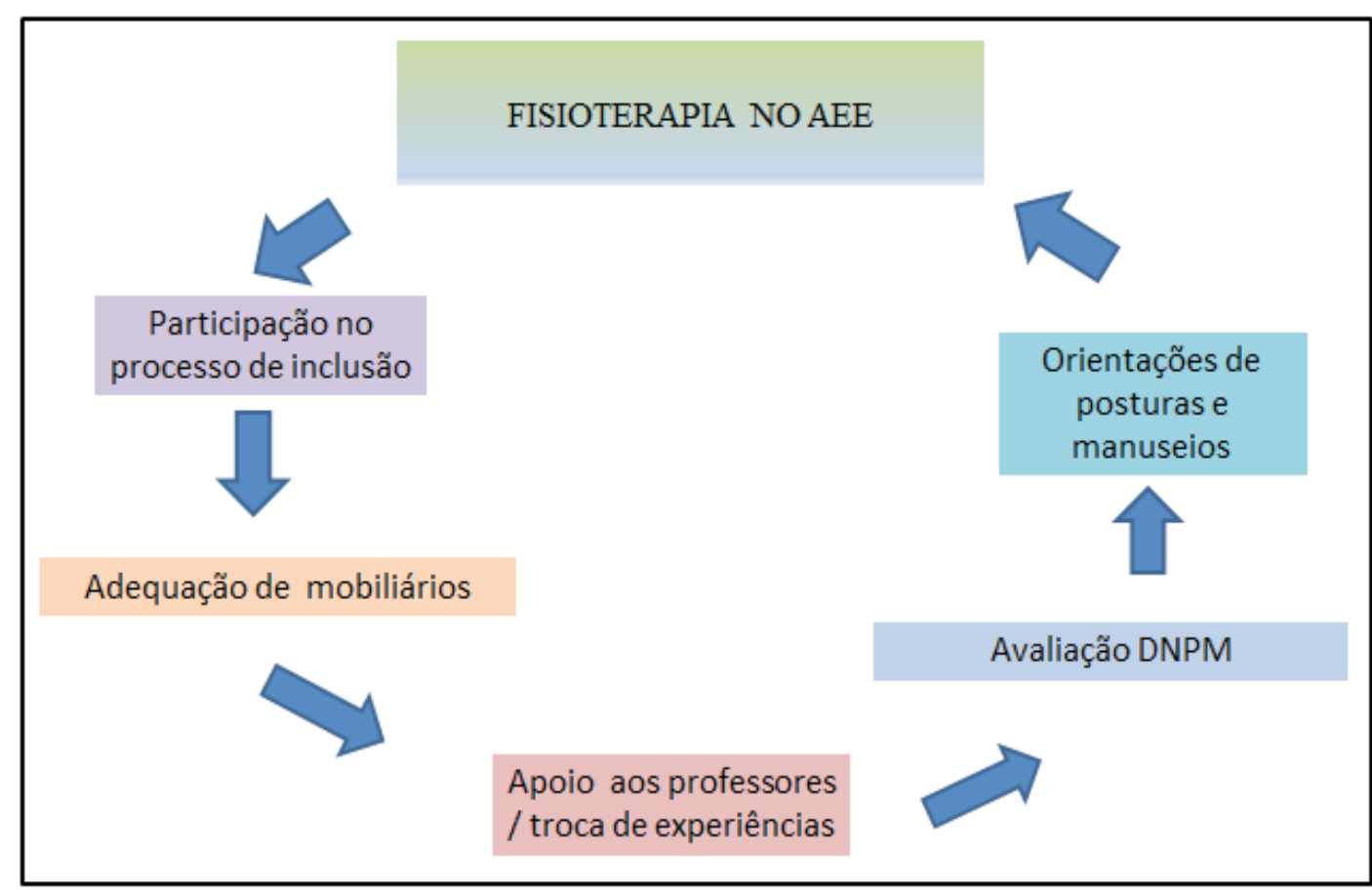

Fonte: As autoras (2016).

\section{CONSIDERAÇÕES FINAIS}

Por meio deste estudo evidencia-se a importância do profissional fisioterapeuta atuando interdisciplinarmente com outros profissionais, no ambiente educacional, assim como é realizado na atenção primária em saúde, na qual se preconiza a prevenção por meio de estratégias de educação em saúde. Conclui-se também, que para uma efetiva inclusão escolar, é indispensável a atuação conjunta de uma equipe interdisciplinar, podendo o fisioterapeuta exercer um importante papel em vários sentidos como: adaptações de mobiliários, orientações aos educadores quanto aos manuseios com os alunos com deficiência e também dúvidas referentes ao desenvolvimento neuropsicomotor, por exemplo. Assim como, capacitações aos professores, tendo o fisioterapeuta como colaborador, para sanar dúvidas e orientar este profissional da educação. Pois se sabe da dificuldade que esses profissionais encontram para trabaIhar com esses alunos e a falta de capacitações.

É necessário que haja uma quebra de paradigmas em relação à atuação do fisioterapeuta, já que culturalmente, conhece-se mais a área de atuação com o foco curativo / reabilitador. Ou seja, há a necessidade do fisioterapeuta também reconhecer que o ambiente escolar é um espaço que ele possa atuar, assim como os gestores da educação. Necessitam-se também, mais estudos relacionados à temática, já que se obtiveram dificuldades para a elaboração desse estudo e divulgar o trabalho da fisioterapia para a comunidade escolar.

\section{REFERÊNCIAS}

ALPINO, Â. M. S. Consultoria colaborativa escolar do fisioterapeuta: acessibilidade e participação do aluno com paralisia cerebral em questão. 2010. Doutorado em Educação Especial, Universidade Federal de São Carlos, São Carlos.

BRAGA, A. K. P.; RODOVALHO, J. C.; FORMIGA, C. K. M. R. Evolução do crescimento e desenvolvimento neuropsicomotor de crianças pré-escolares de zero a dois anos do município de Goiânia (GO). Revista brasileira de crescimento e desenvolvimento humano, v. 21, n. 2, p. 230239, 2011. ISSN 0104-1282.

BRASIL. SEESP: Política Nacional de Educação Especial na Perspectiva da Educação Inclusiva. Documento elaborado pelo Grupo de Trabalho nomeado pela Portaria Ministerial, n. 555, 2008. 
BRIDI, F. Atendimento educacional especializado. Reflexão e Ação, v. 17, n. 1, p. 42-56, 2009. ISSN 1982-9949.

CHESANI, F. H.; CORDEIRO, D. S.; BARBOZA, K. M.; KERKOSKI, E. A contribuição da fisioterapia na formação do professor de ensino regular na educação inclusiva. Revista de Educação Popular, v. 14, n. 1, p. 85-96, 2015. ISSN 1982-7660.

COFFITO. Legislação que regulamenta a atividade de Fisioterapia. DECRETO LEI N. 938, DE 13 DE OUTUBRO DE 1969.

COSTA, L. O.; MAHER, C. G.; LOPES, A. D.; DE NORONHA, M. A.; COSTA, L. C. Como escrever de forma transparente artigos científicos relevantes para a prática da Fisioterapia. Rev Bras Fisioter, v. 15, n. 4, p. 267-71, 2011.

DE-LA-TORRE-UGARTE, M. C.; TAKAHASHI, R. F.; BERTOLOZZI, M. R. Revisão sistemática: noções gerais. Revista da Escola de Enfermagem da USP, v. 45, n. 5, p. 1260-1266, 2011. ISSN 1980-220X.

DURCE, K.; FERREIRA, C.; PEREIRA, P. S.; SOUZA, B. B. A atuação da fisioterapia na inclusão de crianças deficientes físicas em escolas regulares: uma revisão da literatura. 0 mundo da saúde, v. 3, n. 1, p. 156-159, 2006.

FERRAZ, C. R. A.; ARAÚJO, M. V. D.; CARREIRO, L. R. R. Inclusão de crianças com Síndrome de Down e paralisia cerebral no ensino fundamental I: comparação dos relatos de mães e professores. Rev. bras. educ. espec, v. 16, n. 3, p. 397-414, 2010. ISSN 1413-6538.

GALLO, E. C.; ORSO, K. D.; FIÓRIO, F. B. Análise da acessibilidade das pessoas com deficiência física nas escolas de Chapecó-SC e o papel do fisioterapeuta no ambiente escolar. Mundo saúde (Impr.), v. 35, n. 2, p. 201-207, 2011. ISSN 0104-7809.

GUIMARÃES, F. A. D. B.; ASSIS, C. D.; VIEIRA, M. E. B.; FORMIGA, C. K. M. R. Avaliação de material didático elaborado para orientação de cuidadores e professores de creches sobre o desenvolvimento infantil. Revista brasileira de crescimento e desenvolvimento humano, v. 25, n. 1, p. 27-40, 2015. ISSN 0104-1282.

JORQUEIRA NETO, A. C.; BLASCOVI-ASSIS, S. M. Contribuições do fisioterapeuta na inclusão escolar de alunos com deficiência sob a perspectiva do brincar. Cadernos de Pós-Graduação em Distúrbios do Desenvolvimento, v. 9, n. 1, p. 76-91, 2009.

KASSAR, M. D. C. M.; REBELO, A. S. O" especial" na educação, o atendimento especializado e a educação especial. SEMINÁRIO NACIONAL DE PESQUISA EM EDUCAÇÃO ESPECIAL. Prática Pedagógica na Educação Especial: multiplicidade do atendimento educacional especializado, v. 4, 2011.
KAVALCO, T. F. A eficácia de orientações de posicionamentos sentados e funcionais aplicadas no domicílio para família de uma criança portadora de paralisia cerebral: um estudo de caso 2003 . (Graduação). Curso de fisioterapia Universidade Estadual do Oeste do Paraná, Cascavel.

LANDMANN, L. M.; RUZZA, P.; CHESANI, F. H. Espaço educacional e a possibilidade de atuação do fisioterapeuta. Ciências \& Cognição, v. 14, n. 3, p. 83-91, 2009. ISSN 18065821.

LIMA E SILVA, L. J. A. D.; MAZZOTTA, M. J. D. S. Importância da inclusão escolar na reabilitação fisioterapêutica de crianças com paralisia cerebral. Cadernos de Pós-Graduação em Distúrbios do Desenvolvimento, v. 9, n. 1, p. 9-32, 2009.

MACHADO, F. As dificuldades do aluno portador de deficiência física no processo de adaptação social em escola regular no município de Porto Alegre. Monografia). Canoas: Universidade Luterana do Brasil, 1999.

MELO, F. R. L. V. D.; FERREIRA, C. C. D. A. O cuidar do aluno com deficiência física na educação infantil sob a ótica das professoras. Rev. bras. educ. espec, v. 15, n. 1, p. 121-140, 2009. ISSN 1413-6538.

MELO, F. R. L. V. D.; PEREIRA, A. P. M. Inclusão escolar do aluno com deficiência física: visão dos professores acerca da colaboração do fisioterapeuta. Rev. bras. educ. espec, v. 19, n. 1, p. 93-106, 2013. ISSN 1413-6538.

MORAES, L. R. S. A formação do fisioterapeuta quanto à inclusão escolar de crianças com deficiência física. 2004. Dissertação, Universidade Presbiteriana Mackenzi, São Paulo.

NIEHUES, J. R.; NIEHUES, M. R. Educação Inclusiva de Crianças com Deficiência Física: Importância da Fisioterapia no Ambiente Escolar. Revista Neurociências, v. 22, n. 1, p. 113-120, 2014.

ROTHER, E. T. Revisão sistemática $X$ revisão narrativa. Acta Paulista de Enfermagem, v. 20, n. 2, p. v-vi, 2007. ISSN 0103-2100.

SAMPAIO, R. F.; MANCINI, M. C. Estudos de revisão sistemática: um guia para síntese criteriosa da evidência científica. Braz. J. Phys. Ther.(Impr.), v. 11, n. 1, p. 83-89, 2007. ISSN 1413-3555.

SANTOS, M. E. T. D.; LARA, S.; FOLMER, V. Inclusão escolar: possíveis contribuições da fisioterapia sob a óptica de professoras. Revista Educação Especial, v. 1, n. 1, p. 67-82, 2014. ISSN 1984-686X. 
SARAIVA, L. L. O.; MELO, F. R. L. V. D. Avaliação e participação do fisioterapeuta na prescrição do mobiliário escolar utilizado por alunos com paralisia cerebral em escolas estaduais públicas da rede regular de ensino. Rev. bras. educ. espec, v. 17, n. 2, p. 245-262, 2011. ISSN 1413-6538.

SILVA, F. K. R.; DOS SANTOS, D. N.; FUMES, N. D. L. F. Os Professores de educação física escolar e o atendlmento educacional especializado nas escolas Públicas. Revista da Associação Brasileira de Atividade Motora Adaptada, v. 15, n. 02, p. 31-36, 2014. ISSN 2359-2974.

SILVA, S. M.; SANTOS, R. R. D. C. N.; RIBAS, C. G. Inclusion of students with cerebral palsy in elementary education: contributions of physiotherapy. Revista Brasileira de Educação Especial, v. 17, n. 2, p. 263-286, 2011. ISSN $1413-$ 6538.

TAGLIARI, C.; TRÊS, F.; OLIVEIRA, S. G. D. Análise da acessibilidade dos portadores de deficiência física nas escolas da rede pública de Passo Fundo e o papel do fisioterapeuta no ambiente escolar. Revista Neurociências, v. 14, n. 1, p. 10 14, 2006.

VITTA, F. C. F. D.; SANCHEZ, F. F.; PEREZ, R. R. Desenvolvimento motor infantil: avaliação de um programa de educação para berçaristas. MIMESIS, v. 1982, n. 2000, p. 101, 2000. 